\title{
ANÁLISE RETÓRICO-TEXTUAL DO GÊNERO CARTA DO LEITOR NA ESFERA ACADÊMICA
}

\author{
Cláudia Amorim de ALMEIDA ${ }^{1}$ \\ Especialista em Linguagem e Práticas Sociais pela PGLPS do IFAL, Campus Murici \\ Ricardo Jorge de Sousa CAVALCANTI ${ }^{2}$ \\ Doutor em Letras e Linguística pela UFAL \\ Pós-doutorando em Linguística Aplicada pela UFAL \\ Professor efetivo do Instituto Federal de Alagoas, Campus Maceió \\ Professor Permanente do ProfEPT/IFAL, Campus Benedito Bentes
}

\begin{abstract}
RESUMO: Este estudo aborda, com base na produção do gênero Carta do leitor por participantes de um minicurso, o sujeito como agente sócio-histórico e discursivo em práticas linguageiras argumentativas escritas. Para tanto, elegemos estudos que tratam da Nova Retórica (REBOUL, 2004; PERELMAN e OLBRECHTS-TYTECA, 2005) na inter-relação com a Linguística Textual (KOCH, 2015; KOCH e ELIAS, 2016; MARCUSCHI, 2008; 2010; 2011). $\mathrm{O}$ trabalho com a Carta do leitor se deu pelo seu potencial argumentativo e também didático. A pesquisa se caracteriza como uma pesquisa-ação, numa perspectiva qualitativa de investigação, a partir da produção e análise de dados autênticos. Os resultados apontam, considerando a experiência realizada, certa dificuldade na elaboração do gênero Carta do leitor por parte dos sujeitos produtores: licenciandos e licenciados nos Cursos de Letras e de Pedagogia de um dado contexto. Tal constatação nos leva a defender a importância do trabalho sistematizado com a argumentação na formação inicial/continuada docente.
\end{abstract}

Palavras-chave: Argumentação. Carta do leitor. Produção textual escrita.

\section{Introdução}

A Carta do leitor é um gênero que há muito ocupa os folhetins impressos da mídia jornalística. Por meio desse gênero, os leitores podem opinar acerca de um tema anteriormente difundido em outros gêneros, como a notícia, o artigo de opinião e, até mesmo, a própria Carta do leitor. Com base nisso, motivamo-nos a investigar, a partir de um minicurso ministrado, intitulado "Saberes necessários à produção de textos argumentativos na Educação Básica e no Ensino Superior: da teoria à prática” (2018), como os sujeitos participantes de tal ação, professores em formação inicial (licenciandos) e professores licenciados, produziriam o gênero Carta do leitor e quais estratégias de convencimento/persuasão utilizariam para a demonstração de seus pontos de vista.

\footnotetext{
${ }^{1}$ Endereço eletrônico: amorimclaudia70@yahoo.com

${ }^{2}$ Endereço eletrônico: richardcavalcanti@ hotmail.com
} 
O objetivo principal da pesquisa foi reconhecer, por meio da produção da Carta do leitor, o sujeito como agente sócio-histórico e discursivo, empoderado, a partir de práticas linguageiras mais cidadãs, visto que consideramos ser de fundamental importância posicionarse socialmente/ideologicamente, uma vez que a palavra é o encontro que se estabelece com o outro, em termos bakhtinianos (BAKHTIN, 2003) e, por extensão, é o contato direto pelo qual podemos nos fazer valer no mundo, demarcando-nos. Assim, ao lançar mão de argumentos verossímeis, mais próximos estaremos de nossos interlocutores em processos interativos.

A discussão se justifica pela dificuldade que têm os sujeitos, nas diversas etapas de escolarização - na educação básica e no ensino superior -, conforme atestam Cavalcanti (2010; 2016) e Almeida (2018), para emitirem juízos de valor sobre temas que estão correntemente na sociedade e que requerem opiniões bem fundamentadas a fim de que possam não apenas se posicionar, mas também estabelecer um diálogo com o outro, inclusive utilizando estratégias de refutação para aquilo que fora apresentado/debatido. Nesse sentido, a Carta do leitor cumpre, em alguma medida, tal desiderato: o de promover sujeitos mais empoderados linguisticamente por meio do uso de argumentos que enalteçam a sua tese/ o seu ponto de vista.

Como já antecipamos, o presente estudo faz parte de uma pesquisa-ação (THIOLLENT, 1986) que visou ao ensino da produção de um texto opinativo-argumentativo, a Carta do leitor, por meio da oferta de um minicurso de $8 \mathrm{~h} / \mathrm{a}$, dividido em dois dias, realizado no Instituto Federal de Alagoas, Campus Maceió, contemplando participantes (colaboradores) licenciados e licenciandos, dos Cursos de Letras e de Pedagogia. Com efeito, o corpus foi constituído por 3 (três) produções escritas, elaboradas por 06 (seis) sujeitos que participaram integralmente dos dois momentos destinados à oficina do gênero Carta do leitor, no primeiro semestre de 2018.

Como base teórico-conceitual para proceder ao nosso estudo, estabelecemos diálogos com autores que tratam da Nova Retórica, a exemplo de Reboul (2004); Perelman e Olbrechts-Tyteca (2005); Abreu (2009) e Fiorin (2014; 2017). Ademais, como o nosso trabalho se insere nos estudos retóricos na inter-relação com a Linguística Textual, autores como Koch (2015; 2016) e Marcuschi (2008; 2010; 2011); além de Bezerra (2010), no entendimento do gênero Carta do leitor, também nos foram igualmente relevantes ao estabelecimento de nossa discussão.

Dessa forma, os tópicos que seguem esta discussão se prestam a, primeiramente, contextualizar a Retórica em seu percurso histórico, que inicia com os gregos antigos - e o 
seu declínio - ao ressurgimento, a chamada Nova Retórica. Em seguida, tecer algumas considerações acerca de elementos que fundamentam a textualidade para um entendimento mais cuidadoso acerca das práticas de produção textual numa perspectiva sociointeracional. Sequencialmente, estabelecer considerações sobre a argumentação, fator inerente ao ato de persuadir pelo discurso; e, progressivamente, apresentar a seleção do corpus e os procedimentos de análise utilizados. Por fim, discutir os resultados, por meio das análises empreendidas neste estudo linguístico-textual e retórico-discursivo.

\section{O primórdio da Retórica}

A palavra Retórica é de origem grega “rhéseis" e quer dizer ‘ação da fala', ‘discurso'. Assim, Rhetoriké é a arte oratória de convencer pelo discurso" (FIORIN, 2014, p. 9). São ouvidos, frequentemente, muitos relatos sobre as suas raízes; isso porque há, entre alguns teóricos, controvérsias em relação à sua origem. Nessa linha de raciocínio, Reboul (2004, p. 1) assevera que a "retórica é anterior à sua própria história, e mesmo a qualquer história, pois é inconcebível que os homens não tenham utilizado a linguagem para persuadir”. Para compreender melhor a seu respeito, importa, de algum modo, entender previamente de onde surgiram suas técnicas, características e formas de utilização.

Segundo Abreu (2009), a Retórica surgiu na antiga Grécia por volta de 427 a.C. junto ao desenvolvimento da Democracia e, em particular, à necessidade social de preparar os cidadãos que pretendiam exercê-la. Em função do ato democrático, era imprescindível que os atenienses soubessem fazer uso competente da oratória, não apenas para terem voz mas também para se inserirem na Política.

Os sofistas, que eram seguidores de Aristóteles e professores de Retórica, contrapunham-se à existência da verdade, ou seja, segundo eles, não havia verdade universal, todas eram transitórias. Para eles, o que existiam eram convenções e pontos de vista efêmeros, entretanto, em momento algum considerados como falsos e verdadeiros. Segundo Abreu (2009), foi esse tipo de pensamento que deve ter ocasionado a famosa declaração de Protágoras: "o homem é a medida de todas as coisas". Os sofistas afirmavam, inclusive, que a verdade é subjetiva. Isso quer dizer que "as coisas são como aparecem a cada homem; não há outro critério de verdade" (REBOUL, 2004, p. 8). Tal afirmação se configura como o mais absoluto relativismo, uma vez que, nessa ótica, não existia uma verdade objetiva, mas uma verdade pertencente a cada indivíduo. 
Nesse sentido, temos a Retórica Clássica sob duas vertentes. Uma delas é a Retórica dos sofistas, fundamentada no verossímil, que consiste na utilização de argumentos lícitos e não lícitos (verossímeis). A outra é a Retórica dos filósofos, proferida, principalmente, por Sócrates e Platão, cujo pensamento era "defender a teoria do ponto de vista ou paradigmas, aplicados sobre o objeto de seu estudo" (ABREU, 2009, p. 28).

Para compreender o repúdio desses filósofos à Retórica sofista, é necessário se entender a Retórica filosófica, que, ao contrário da dos sofistas, tinha compromisso com a verdade e concede ao auditório a possibilidade de concordar com a tese do orador, por meio de reflexões, debates e questionamentos, opondo-se, consequentemente, ao relativismo.

A Retórica Antiga (Clássica) era vista como uma modalidade discursiva que consistia na arte da comunicação, usada com o objetivo unicamente de persuadir. Entre os antigos, segundo Perelman e Olbrechts-Tyteca (2005, p. 7), “a retórica se apresentava como o estudo de uma técnica para o uso do vulgo, impaciente por chegar rapidamente a conclusões, por formar uma opinião para si, sem se dar ao trabalho prévio de uma investigação séria [...]”.

Provavelmente, foi essa definição de Retórica que descreve a atitude que Platão assumiu para combater com tanto esforço a Retórica dos sofistas, e isso contribuiu para a sua decadência no conceito filosófico. Em síntese, com base no que foi tratado, pode-se perceber a diferença entre a Retórica dos filósofos daquela praticada pelos sofistas.

\section{Argumentação e sua dimensão}

Em seu livro A arte de argumentar, Abreu (2009) expressa a ligação entre Retórica e a essência da palavra argumentação, ressaltando a notória importância da técnica argumentativa ao contribuir para a construção do discurso persuasivo. Concernente a isso, é preciso enfatizar que os termos argumentação e Retórica estão intimamente relacionados. Embora a argumentação dê origem ao convencimento enquanto a persuasão advém dos princípios da Retórica Clássica (REBOUL, 2004), nessa lógica de distinção retórica, ao convencer alguém, está se tratando do racional; e ao persuadir alguém, lida-se com as emoções e sentimentos, sobretudo, comovendo e induzindo-o à ação.

Nessa perspectiva, julgamos necessário expor a diferença entre persuadir e convencer. Para Abreu (2009), a argumentação se resume à arte de convencer e persuadir. Segundo o referido autor, convencer é ser capaz de gerenciar informação, é falar à razão do outro. Ao convencer uma pessoa, ela passa a raciocinar de forma filiada ao seu retor, não de forma induzida, mas de forma autônoma. Por sua vez, persuadir é conseguir articular a 
emoção do outro, é comover o outro para agir. Para Reboul (2004), no entanto, os limites entre o convencimento e a persuasão no ato discursivo são tênues, por isso, em algumas abordagens, prefere-se tomar tais termos como, em certa medida, sinônimos, já que a demarcação entre um e outro se imbrica.

Em relação ao uso da argumentação, Perelman e Olbrechts-Tyteca (2005) abordam que a sua utilização se relaciona com o propósito que se pretende alcançar: "para quem se preocupa com resultado, persuadir é mais do que convencer, pois a convicção não passa da primeira fase que leva à ação. [...] Em contrapartida, para quem está preocupado com o caráter racional da adesão, convencer é mais que persuadir" (PERELMAN; OLBRECHTSTYTECA, 2005, p. 30).

Outro apontamento dos referidos autores é a diferenciação entre os tipos de argumento, conforme seus respectivos auditórios. Esses autores, em seu Tratado, sugerem "chamar persuasiva uma argumentação que pretende valer só para um auditório particular e chamar convincente àquela que deveria obter a adesão de todo ser racional" (PERELMAN; OLBRECHTS-TYTECA, 2005, p. 31). Com base nisso, a seguir, trataremos dos tipos de argumento a fim de que, com base em suas definições, possamos nos valer de tais elementos retórico-discursivos como categorias de análise no gênero Carta do leitor produzido pelos participantes do presente estudo.

\section{Tipos de argumento}

Com referência às técnicas argumentativas, a obra Tratado da Argumentação, de Perelman e Olbrechts-Tyteca (2005), descreve quatro grupos de argumentos: 1) os quase lógicos; 2) os baseados na estrutura do real; e 3) as ligações que fundamentam a estrutura do real; e 4) os que dissociam uma noção. Para fins de delimitação de nosso estudo, tratamos de argumentos pertencentes aos segundo e terceiro grupos, na consideração da especificidade conceitual deles e que nos serviu para análise do corpus produzido - o gênero Carta do leitor.

\section{Os argumentos baseados na estrutura do real}

Este segundo grupo de argumentos é baseado na estrutura do real, cuja caracterização é a admissão de pontos de vista. No tocante aos fatos, "valem-se da sua essência para estabelecer uma solidariedade entre juízos admitidos e outros que se procuram promover", portanto, entendemos que os argumentos baseados na estrutura do real se constroem pelas ligações de sucessão. Eles estabelecem uma união entre um episódio e suas consequências ou 
suas causas (PERELMAN; OLBRECHTS-TYTECA, 2005, p. 297). Nesse grupo, elegemos, para fins de delimitação deste trabalho, o argumento de direção e o argumento de autoridade, que discorreremos a seguir.

\section{O argumento de direção}

Para Perelman e Olbrechts-Tyteca (2005, p. 321), o argumento de direção "consiste essencialmente, no alerta contra o uso do procedimento das etapas: se você ceder esta vez, deverá ceder um pouco mais na próxima, e sabe Deus aonde vai parar”.

Esses autores ainda abordam que o argumento da direção visa sempre advertir sobre práticas ou situações fundamentadas no risco que é ceder a algumas etapas aparentemente inocentes, pois pode acarretar em questões perigosas.

\section{$O$ argumento de autoridade}

$\mathrm{O}$ argumento de autoridade é direcionado pelo prestígio, cuja validade justifica-se pelo fato de que "utiliza atos ou juízos de uma pessoa ou de um grupo de pessoas como meio de prova a favor de uma tese" (PERELMAN; OLBRECHTS-TYTECA, 2005, p. 348). Isto é, a tese se sustenta pela palavra de honra, que pode ser dada por todo aquele que possua prestígio socialmente reconhecido.

\section{As ligações que fundamentam a estrutura do real}

Este terceiro grupo, e último do esboço de nossa conceituação sobre os tipos de argumento, por sua vez, atua não na estrutura do real, mas a partir de fundamentos que empregam recursos para fundamentar a estrutura do real. Nesse grupo, podemos destacar a argumentação pelo modelo (e antimodelo); e os lugares da argumentação.

\section{Argumentação pelo modelo (e antimodelo)}

Argumentação pelo modelo, na prática, é entendida sempre que se faz valer de alguma coisa ou de alguém que sirva para estimular uma ação nela inspirada. No entanto, nem todos podem ser tomados para servirem de modelo, exceto se possuírem certo prestígio socialmente reconhecido. A esse respeito, Perelman e Olbrechts-Tyteca (2005, p. 414) apresentam quem pode servir de modelo: "pessoas ou grupos cujo prestígio valoriza os atos. Não se imita qualquer um; para servir de modelo é preciso um mínimo de prestígio”. Em 
oposição a essa citação, há um antimodelo, do qual, no ato argumentativo, é recomendável nos afastar ou nos aproximar como medida de refutação.

\section{Os lugares da Argumentação}

Segundo Perelman e Olbrechts-Tyteca (2005, p. 95), "os lugares formam um arsenal indispensável, do qual, de um modo ou de outro, quem quer persuadir outrem deverá lançar mão". Assim, a recorrência aos lugares retóricos da quantidade e da qualidade se constitui como relevante estratégia argumentativa à promoção do convencimento/da persuasão no auditório.

\section{Lugares da quantidade}

O lugar da quantidade, em sentido amplo, entende-se como aquele em "que alguma coisa é melhor do que outra por razões quantitativas". De outro modo, podemos considerar como características do lugar de quantidade não somente os números e estatísticas, mas também as questões em que se aplica a superioridade em relação aos valores positivos quanto aos negativos; a preferência pelo provável ao improvável; ao fácil sobre o difícil, entre outros. Logo, este lugar de argumentação ajuda o orador a escolher argumentos que se pautam em elementos quantitativos (PERELMAN; OLBRECHTS-TYTECA, 2005, p. 97).

\section{Lugares de qualidade}

O lugar de qualidade apresenta oposição ao lugar de quantidade, pois preza pelo único, pelo raro e, por extensão, contesta os números. Abreu (2009, p. 89), atribuindo um exemplo, toma uma máxima de Sêneca: "ninguém ama sua pátria porque ela é grande, mas porque é sua." Aqui, segundo o autor, o lugar de qualidade se explica pelo "fato de alguém ter uma única pátria assume um valor maior do que a quantidade de seu território". Podemos afirmar, a partir do enunciado, que "o único é original, distingue-se, por isso é digno de nota e agrada mesmo a multidão" (PERELMAN; OLBRECHTS-TYTECA, 2005, p. 102). Considerando-se que os lugares de qualidade são tratados como atos retóricos que ensejam a recorrência àquilo que é raro e único, nesse contexto, podem-se destacar: o lugar de ordem; o lugar de essência; o lugar de pessoa; e o lugar do existente. Entre esses lugares, trataremos, em específico, do lugar de essência, categoria essa que estará presente no corpus discutido. 


\section{O Lugar de essência}

O lugar de essência se volta a uma espécie de comparação entre indivíduos e até mesmo entre objetos. Sendo definido como "o fato de conceder um valor superior aos indivíduos enquanto representantes bem caracterizados dessa essência" (PERELMAN; OLBRECHTS-TYTECA, 2005, p. 106).

Objetivando estabelecer uma inter-relação entre os estudos argumentativos retóricos e os relacionados à textualidade, a seguir, serão apresentados alguns preceitos relacionados à textualidade numa perspectiva linguístico-discursiva, cuja recorrência se dá por meio da produção de exemplares de textos autênticos que têm uma grande mobilidade social, como é o caso da Carta do leitor.

\section{Abordagens textual-discursivas em práticas sociais}

Segundo Bakhtin (apud FIORIN, 2017, p. 69), "os gêneros são tipos de enunciados relativamente estáveis, caracterizados por um conteúdo temático, uma construção composicional e um estilo". Essas três dimensões representam elementos constituintes à elaboração dos gêneros do discurso. Em síntese, essas características configuram diferentes gêneros que podem estar marcados na inter-relação entre linguagem e práticas sociais, já que se concebe que tais enunciações compõem um conjunto de práticas de linguagem relativamente estereotipadas em diversas esferas de atuação humana.

Marcuschi (2008, p. 154) reitera que "toda manifestação verbal se dá sempre por meio de textos realizados em algum gênero". Isso porque, em nossa rotina cotidiana, nos "deparamos" com diversos textos, sejam eles escritos ou orais - e ainda, multimodais -, que se caracterizam prototipicamente como um gênero específico. Desse modo, seja qual for o acontecimento em que o texto-discurso estiver presente, há um gênero relacionado àquele contexto social, visto que nos comunicamos acessando o exemplar de gênero correspondente a dada situação linguageira e, em momentos de maior flexibilização, reelaborando-o.

Marcuschi (2008, p. 194), em estreito diálogo com Bakhtin (2003), alega que os textos situam-se em domínios discursivos compreendidos como "uma esfera da vida social ou institucional (religiosa, jurídica, jornalística, pedagógica, política, industrial, militar, familiar, lúdica, etc.)". De acordo com essa abordagem, há de se compreender que cada domínio discursivo, que para Bakhtin são esferas de atividade humana, abrange gêneros específicos. Não é descartada aqui a possibilidade, dados os propósitos da enunciação, de deslocamento e 
de intercruzamento dos gêneros textuais-discursivos, conforme tratamos anteriormente ao utilizarmos o termo "flexibilização".

Bakhtin (2003), em seu ensaio sobre gêneros do discurso, divide os gêneros em duas categorias: primários e secundários, considerando não apenas a sua complexidade de elaboração, sobretudo, do segundo grupo em relação ao primeiro, mas para asseverar que todo gênero secundário, antes de tudo, precisou ser primário. Na primeira categoria, são englobados os gêneros da vida cotidiana, por exemplo, a piada, o e-mail, o chat, o bilhete etc. Já os gêneros secundários pertencem à esfera da comunicação cultural mais elaborada, por exemplo, o artigo científico, o editorial e assim por diante, os quais, como já tratamos, advêm dos primários.

Em virtude de serem incalculáveis as ações humanas, não há como enumerar todos os gêneros existentes, sobretudo ao se considerarem as práticas diversificadas de oralidade e de escrita existentes e reelaboradas constantemente. Nesse tocante, há de se reconhecer, que isso varia de cultura para cultura, considerando a existência de sociedades grafocêntrica; ao tempo em que são percebidas, em contextos variados, sociedades de cultura ágrafa. Com efeito, para Marcuschi (2011), tal intenção de catalogação seria impossível em decorrência da dinamicidade que se estabelecem as práticas linguageiras. Não se pode deixar de enfatizar, ainda nesse mesmo ponto, que tal maleabilidade faz com que os gêneros sejam dinâmicos e plásticos, ocorrendo variações em sua composição, uma vez que surgem e se renovam conforme as necessidades e atividades socioculturais. O próprio gênero que elegemos para o estabelecimento de nosso estudo, a Carta do leitor, não à toa carrega em seu título a sua origem, mas também guarda características prototípicas do gênero carta, que também se desdobrou em gêneros semelhantes à sua estrutura composicional, inclusive, possibilitando formas de composição híbridas.

\section{Operadores Argumentativos}

Ducrot (apud Koch, 2015, p. 29-30) afirma que "a argumentatividade está inscrita na própria língua". O autor, criador da Semântica Argumentativa, cunhou o termo operadores argumentativos para os elementos que não somente dão progressividade ao texto-discurso, mas que também servem para estabelecer relações interfrasais (coesão sequencial) em sequências enunciativas. Para ele, toda língua possui em sua estrutura gramatical elementos linguístico-enunciativos responsáveis por expor a intenção do produtor do texto. Eles, por sua 
vez, "têm por função indicar ou mostrar a força argumentativa dos enunciados, a direção ou sentido para o qual apontam" (KOCH; ELIAS, 2016, p. 61).

Diversos são os tipos de operadores argumentativos, como destaca Koch (2015, p. 31-39) em seu livro A Inter-ação pela Linguagem para o estabelecimento da argumentação no plano linguístico. Essa mesma autora, numa relação análoga entre esses operadores e as conjunções gramaticais, já preferiu chamá-los de conectores interfrasais (CAVALCANTI, 2010). Na Linguística Textual, considerando os aspectos voltados à coesão sequencial ou no plano de estudos relacionado à Argumentação na Língua, os operadores argumentativos ganham relevo ao serem concebidas as relações sintático-semânticas como potencialmente estabelecedoras de sequências argumentativas. Em suma, como bem nos assevera Koch (2015), é de fundamental importância saber selecionar os operadores de forma adequada quando a intenção é argumentar de modo coerente, coeso e eficaz, haja vista que uma escolha inadequada pode comprometer a intensidade argumentativa do texto-discurso e, como consequência, não se obter o efeito argumentativo almejado.

\section{A Carta do leitor no ensino de Língua Portuguesa}

A Carta do leitor é um importante gênero para o exercício da cidadania. Configurase como um texto argumentativo, já que tem por objetivo expor e defender/apresentar o ponto de vista do leitor/interlocutor, principalmente, acerca de um assunto polêmico, de interesse social circulado em alguma mídia comunicativa. Segundo Melo (apud BEZERRA, 2010, p. 228), a Carta do leitor é um "texto que circula no contexto jornalístico, em seção fixa de revistas e jornais, denominada comumente de cartas, cartas à redação, carta do leitor, painel do leitor reservada à correspondência dos leitores".

Na visão de Bezerra (2010, p. 228), a Carta do leitor cumpre o propósito de tornar possível a interação entre interlocutores ausentes, ou seja, que não se conhecem no debate de um tema difundido em algum dos veículos de comunicação midiáticos. Tais veículos são também considerados, numa abordagem discursiva, como um campo de atuação humana da linguagem, cujas efervescência e liquidez das informações são comumente discutidas. Nesse exemplar de gênero, o sujeito leitor e futuro produtor textual-discursivo pode opinar, reclamar, solicitar, elogiar, e criticar, seguindo a mesma linha de raciocínio de Bezerra (2010).

A respeito do desenvolvimento de práticas de linguagem em contextos escolares e acadêmicos, parte-se do pressuposto que é por meio de práticas de produção de gêneros nas 
modalidades oral e escrita que os alunos são vistos como agentes sociais, sendo exatamente no contexto escolar, e também no acadêmico, que eles precisam desenvolver habilidades para criar, observar e avaliar argumentos seus e de outros sujeitos. Com efeito, "o texto escrito deve ser o mais autônomo possível não só no que diz respeito à clareza e à quantidade de informações necessárias, como também, principalmente, no que toca aos procedimentos argumentativos" (FIORIN; SAVIOLI, 2007, p. 201).

Nessa perspectiva de produção de textos a partir da representação dos gêneros na escola, Schneuwly e Dolz (2004, p. 68) destacam:

[...] a representação do gênero na escola pode, então, ser descrita como segue: trata-se de levar o aluno ao domínio do gênero, exatamente como este funciona (realmente) nas práticas de linguagem de referência. Assim, estas últimas constituem, senão uma norma a atingir de imediato, ao menos, um ideal que permanece como um alvo. Decorre daí que textos autênticos do gênero considerado entram tais e quais na escola. Uma vez dentro destas, trata-se de (re)criar situações que devem reproduzir as das práticas de linguagem de referência, como uma preocupação de diversificação claramente marcada. O que é visado é o domínio, o mais perfeito possível, do gênero correspondente à prática de linguagem para que, assim instrumentado, o aluno possa responder às exigências comunicativas com as quais ele é confrontado.

Considerando o exposto pelos autores, a produção textual é vista como uma prática comunicativa que se dá na interação social, pois "é através dos gêneros que as práticas de linguagem materializam-se nas atividades dos aprendizes" (SCHNEUWLY; DOLZ, 2004, p. 63). Dessa forma, a produção textual, de acordo com o proposto, deve ser baseada em situações reais, conforme as necessidades de interação verbal dos sujeitos. Além disso, essa concepção permite a concreta participação dos alunos como sujeitos sociais ativos no exercício de seus papeis em seus processos de ensino e de aprendizagem.

Assim, o ensino de Língua Portuguesa nas escolas deve estar voltado à prática social, principalmente, enfatizando a natureza interacional dos gêneros. O que deve ser bem esclarecido é que a escrita, significativa e motivadora, é, indubitavelmente, uma grande aliada ao processo de ensino e aprendizagem. Por extensão, os professores, nesse processo de ação didática, possibilitam os alunos a operarem com um gênero ao se voltarem às suas atuações sociodiscursivas, levando-se em conta as suas culturas e não somente um simples modo de produzir textos, parafraseando aquilo defendido por Marcuschi (2011, p. 20).

Para Schneuwly e Dolz (2004), a eficiência do processo de ensino e aprendizagem no tocante à leitura e à escrita provém de um ensino dentro de um contexto que tenha sentido 
para o aluno. Situando a produção escrita nesse contexto, o gênero Carta do leitor, em nossa perspectiva, volta-se a essa proposta de ensino, uma vez que representa a verdadeira situação de comunicação por meio da produção de um gênero autêntico. Compete ressaltar ainda que esse gênero abre espaço para o aluno, sujeito produtor, convencer o leitor de que o ponto de vista adotado por ele está fundamentado e, por isso, é passível de aceitação.

No que diz respeito à importância do trabalho com o gênero Carta do leitor em sala de aula, Bezerra (2010, p. 226) confirma sua relevância:

[...] escolhemos o gênero textual carta de leitor, divulgado em revistas, a respeito de notícias ou reportagens publicadas nesse veículo de comunicação, ou solicitações feitas pelos leitores, pois é de fácil acesso, demonstra um contato, por parte deles, com os fatos recentes da sociedade e está escrito em registro formal ou semiformal do português. Além disso, é uma forma concreta de uso da leitura/escrita com função social.

Com base no exposto pela autora, acredita-se, de fato, que o trabalho com esse gênero pode promover a interação dos alunos com os diversos meios de comunicação social; além de permitir-lhes um aprendizado mais efetivo da língua, já que o contato com tal gênero pode lhes possibilitar ler mais criticamente, interpretar e produzir textos com concreta utilidade social; além de, ainda, poder despertar a capacidade do aluno de aprender a organizar o seu raciocínio e, assim, adquirir ideias para utilizar argumentos relativamente mais convincentes.

\section{Metodologia e procedimentos metodológicos para a produção do corpus}

A metodologia para realização e constituição do corpus de nosso trabalho se caracteriza como qualitativa, considerando o processo de produção e análise dos dados; sendo isento o viés estático de produto, já que mesmo considerando o exemplar produzido, leva em conta o processo interlocutivo realizado. Em afinidade com os dizeres de Lüdke e André (1986, p.17), almeja-se que a análise dos dados "seja capaz de reduzir o fenômeno em seus aspectos mais relevantes [...] a fim de melhor compreender e interpretar a realidade.” Assim, ss exemplares que são tomados para análise representam produções autênticas de sujeitos participantes de um minicurso realizado no Campus Maceió, do Instituto Federal de Alagoas (Ifal), promovido pelos professores-pesquisadores, que visou ao trabalho com o gênero Carta do leitor no primeiro semestre de 2018. Para tanto, têm-se, como preceitos, as discussões que tratam da pesquisa-ação (THIOLLENT, 1986), mesmo ao se considerar que o presente estudo contemplou uma ação pontual. No entanto, concernente a esse ponto, há de se salientar a 
relevância da aplicação de experiências de ensino sistematizadas em contextos que se apresentam carentes de ações interventivas. A investigação se prestou a uma atividade de ensino, pesquisa e extensão, uma vez que, nesta última atividade fim, contou com participantes licenciandos do Curso de Letras da própria Instituição promotora; bem como com outros sujeitos licenciandos e licenciados do Curso de Pedagogia, oriundos de outras Instituições de Ensino Superior, públicas e privadas, do contexto local.

Em relação a alguns dos procedimentos metodológicos adotados, o ponto de partida para execução do trabalho, considerando-se as etapas prévias de divulgação e inscrição no minicurso, foi a leitura de textos opinativos, em especial, do gênero artigo de opinião, contemplando discussões acerca do tema feminicídio, a partir de uma publicação online intitulada Precisamos falar sobre feminicídio ${ }^{3}$. A escolha do tema foi feita em função do conteúdo polêmico do texto.O artigo de opinião - gênero originário da esfera jornalística e de considerável argumentação explícita, tanto retórica quanto linguística -, por sua vez, serviu como base para leitura, debate e, por fim, produção textual, considerando o gênero alvo, neste caso, a Carta do leitor, por parte dos sujeitos participantes do minicurso.

\section{O corpus e sua análise}

A seleção do corpus se deu em razão da participação integral dos inscritos na ação realizada, neste caso, no minicurso "Saberes necessários à produção de textos argumentativos na Educação Básica e no Ensino Superior: da teoria à prática”. Sendo assim, o corpus foi constituído por 3 (três) produções de 06 (seis) sujeitos ${ }^{4}$ que participaram dos dois momentos do minicurso destinado ao trabalho com o gênero Carta do leitor.

A análise das cartas foi realizada em dupla e, para um melhor entendimento, a princípio, trazemos, por meio de Figuras, a representação das Cartas produzidas pelos sujeitos, tentando manter a originalidade de suas produções escritas. Logo em seguida, procederemos à análise, por meio de comentários, de cada um desses exemplares produzidos, respeitando-se a respectiva ordem que são dispostos.

\footnotetext{
3. Para acesso a esse texto, conferir o link: http://www.justificando.com/2017/01/04/precisamos-falarsobre-feminicidio/

4- Para fins de preservação da identidade dos sujeitos, os nomes dispostos nas produções são fictícios.
} 
Figura 1- Carta do leitor produzida pela dupla 1

\section{Maceió, 07 de fevereiro de 2018.}

2. Prezado editor,

3. Antes de tudo, queremos parabenizar ao responsável pelo texto que

4. atribuiu visibilidade a um tema tão grave e pouco discutido, que é a

5. violência contra a mulher. É certo que atualmente existe a lei Maria da

6. Penha, mas parece que alguns homens não se sentem intimidados, pois

7. as estatísticas só crescem. Nós mulheres precisamos dar um basta

8. nesta situação. Talvez orientando nossas crianças e jovens para

9. sobretudo respeitar o ser humano.

Auxiliadora,

Joana

Fonte: Dados da pesquisa (2018)

\section{Análise da Carta do leitor 1}

Com base no que se observa na Carta do leitor, já na linha 1, pode-se dizer que o texto manteve em sua estrutura alguns aspectos próprios desse gênero, tais como: começar por um cabeçalho com a informação da cidade onde se encontram suas autoras, a data em que o texto é redigido e o vocativo. Em seguida, na linha 2, o interlocutor é devidamente identificado por um adjetivo - prezado - em que há ideia de apreço. Essa escolha acarreta consequência argumentativa, pois coopera para que o leitor, neste caso, o editor, crie uma imagem das autoras como sensatas; logo, seus argumentos podem ser tidos como dignos de atenção. A partir daí, notadamente, percebe-se o esforço em relação à manutenção da interlocução, por parte das autoras, em todo texto.

Como é possível ver, as autoras iniciam o parágrafo por meio de um articulador de organização textual $\rightarrow$ antes de tudo. Esse elemento conduz o interlocutor no trajeto interpretativo do texto; além de contribuir para uma sucessão de elementos que se interrelacionam na progressão textual. $\mathrm{Na}$ linha 3 , conserva-se a interlocução através do verbo queremos - que, por sua vez, mantém um diálogo com o editor ao elogiar o texto-base por trazer à tona um tema "tão grave e pouco discutido, que é a violência contra a mulher".

Nas linhas 5 e 6, as autoras recorrem à autoridade da Lei Maria da Penha para consolidar a argumentação. Essa lei possui em seu nome uma forte força persuasiva devido à violência doméstica de que foi vítima Maria da Penha. Cabe salientar que tê-la mencionado colabora com o objetivo de convencer e persuadir o interlocutor/leitor por meio da história da vítima. Quanto ao lugar retórico, a Lei Maria da Penha pode ser valorizada pelo lugar de essência, pois a vítima é admirada como sendo representante da luta feminina por justiça. 
$\mathrm{Na}$ linha 7, é possível verificar que há uma mudança no ato retórico-interlocutivo quando as autoras deixam de dialogar com seu primeiro interlocutor, o referido editor, e passam a dialogar com os possíveis interlocutores/leitores, cuja troca é marcada pelo pronome "nós" e pelo imperativo afirmativo "precisamos". Quanto aos operadores argumentativos, na linha 6, o operador argumentativo "mas" demonstra relação lógica de oposição entre os enunciados e conduz o interlocutor/leitor para uma conclusão, ou seja, mesmo com a existência da referida Lei, ainda existem homens que não se sentem intimidados. Já o uso do "pois", na mesma linha 6, explica o enunciado anterior: o aumento das estatísticas.

Por fim, na linha 9, as autoras argumentam utilizando o lugar de qualidade, do único, quando enunciam "respeitar o ser humano". A tese defendida é a de que todo ser humano deve ser respeitado, nesse contexto específico, as mulheres. Nessa passagem, a estratégia persuasiva ocorre por meio de um conselho: orientar as crianças e os jovens a verem o outro por inteiro, mais do que isso, despertar neles noções de valores em relação aos outros sujeitos. Considerando a função social desse texto de teor argumentativo, em que o ponto mais elevado é a defesa de um ponto de vista, compreende-se que o texto dos sujeitos produtores cumpriu razoavelmente tal desiderato.

A seguir, é apresentada, por meio da Figura 2, uma produção representativa de mais uma dupla de participantes, cujo propósito foi apresentar um texto que se configurasse como Carta do leitor no momento destinado à parte final do minicurso ministrado.

Figura 2 - Carta do leitor produzida pela dupla 2

1 O texto da professora Luciana Boiteux, é um relato que acontece

2 frequentemente, a chacina contra as mulheres, caracterizado por

3 relação de poder e submissão praticada por homens sobre mulheres

4 em situação de vulnerabilidade.

5 É horrorizante a forma como as mulheres são tratadas, onde vamos parar?

6 Esse é o tipo de sociedade que queremos?

7 Respeitem as mulheres!

Cristina

Cícera

Fonte: Dados da pesquisa (2018)

\section{Análise da Carta do leitor 2}

O texto apresentado na Figura 2 não conseguiu atender à estrutura básica do gênero Carta do leitor, a começar pela ausência do cabeçalho e por não identificar o interlocutor por meio do vocativo - elemento enunciativo que visa manter, desde o início, a aceitabilidade e a interlocução do/no texto. Entretanto, paralelamente a essa limitação, nas linhas 5 e 6 , o uso da 
primeira pessoa do plural "vamos" e "queremos" projeta, de alguma maneira, um posicionamento das autoras no texto; estabelecendo um diálogo para uma possível adesão do interlocutor/leitor.

$\mathrm{Na}$ linha 2, o marcador temporal "frequentemente" tem função argumentativa de operador argumentativo, pois conduz o leitor a enxergar a forma como as escritoras veem o ato criminoso, isto é, como sendo algo corriqueiro. Ainda inicialmente, pode-se notar o lugar de qualidade utilizado nessa produção. Observa-se que, na continuidade da linha 2, há uma repulsa em relação "a chacina contra mulheres". A partir dessa citação, as autoras fortalecem a argumentatividade desse lugar retórico de essência, argumentando que a vida é uma só, por isso deve ser preservada. O lugar retórico usado nesta produção se vale de uma afirmação de Abreu (2009, p. 88): "tudo aquilo que é ameaçado ganha valor maior".

Cabe destacar como as demais argumentações são construídas em torno de perguntas retóricas. Na linha 5 , as autoras enfatizam suas opiniões críticas à forma hostil como as mulheres são tratadas. A pergunta retórica aparece nesse momento para fazer com que o leitor busque refletir, por meio de um pensamento crítico, sobre as consequências de não denunciar o agressor e mostrar a situação atual de incerteza quanto ao futuro. A pergunta retórica introduzida na linha 6 e com um gesto de resposta logo em seguida, na linha 7, funciona, a nosso ver, como uma estratégia para aproximar, e mais que isso, sensibilizar o interlocutor/leitor da argumentação do texto. Esse movimento retórico é enunciado em forma de apelo, para que os homens valorizem a vida das mulheres e abandonem a prática desrespeitosa como as tratam. O emprego do verbo "respeitem", utilizado no imperativo, consolida esse caráter de apelo e diálogo presente no texto produzido.

A seguir, dispõe-se a Figura 3 para, logo após, proceder à sua análise.

Figura 3 - Carta do leitor produzida pela dupla 3

1. Como sempre vemos em qualquer notícia, mulheres sendo mortas

2. ou sofrendo violência pelos seus companheiros, chegou a hora de mudar

3. essas histórias, nós temos que fazer a diferença e não deixar mais essa

4. situação acontecer.

5. chega de tanta violência!

6. Esse texto nos remete a situações reais, a autora escreveu muito

7. bem a situações de milhões de mulheres do nosso país, além delas existe

8. outras milhares de pessoas sofre com o maxismo e o desrespeito de

9. homens ignorantes, onde eles demostram seu desamor pelo proximo.

10. Respeite a diversidade!

11. Direitos são iguais!

Edna e Verônica 


\section{Análise da Carta do leitor 3}

Fonte: Dados da pesquisa (2018)

Nesse último exemplar produzido, é possível observar, na estrutura disposta pelas autoras, que há um desvirtuamento no que tange às características prototípicas do gênero Carta do leitor, já que optaram por não informar o local, a data, tampouco o vocativo. Paralelamente, nas linhas 1 e 3, parece evidente, o esforço que fazem as autoras do texto por meio da recorrência aos verbos "vemos" e "temos", intencionando estabelecer uma relação de cumplicidade com seu interlocutor/leitor, na demarcação de suas subjetividades. Há de se reconhecer que tal ato retórico é uma estratégia de envolvimento.

Como se pode notar, a carta é iniciada com fatos que já fazem parte da memória social (discursiva) dos leitores: "mulheres sendo mortas ou sofrendo violência pelos seus companheiros" (linhas 1 e 2). Com isso, a apresentação dessa informação relativa à atualidade contribui para introduzir a argumentação do texto, já que é algo que enseja um comprometimento social e cidadão por parte do leitor.

Em relação aos operadores argumentativos, na sequência da linha 2, tem-se uma relação lógica de alternância. As autoras fazem uso do operador "ou" que tem força argumentativa, neste caso, de advertência. Indica que, em alguns casos, quando as mulheres não estão "sendo mortas" estão "sofrendo violência pelos seus companheiros"

$\mathrm{Na}$ linha 5, as autoras fazem uso do intensificador "tanta", que estabelece uma relação de adição entre as palavras, sinalizando que já há bastante violência. Nas linhas 2 e 3 , a estratégia argumentativa das autoras, ao afirmarem que "chegou a hora de mudar essas histórias" e "temos que fazer a diferença e não deixar mais essa situação acontecer" surgem como argumento de direção. Tal argumento visa advertir o interlocutor/leitor que ceder a determinado comportamento abusivo, aparentemente inocente, pode causar situações perigosas. A justificativa da escolha desse argumento pode estar no próprio acontecimento que pertence à realidade.

Outro argumento presente no texto é o argumento de comparação. Nota-se que, nas linhas 7 e 8, a comparação é feita por meio do lugar retórico de quantidade que apresenta dados numéricos para o tratamento da realidade social: "milhões" de mulheres do nosso país, além delas existem outras "milhares" de pessoas. O operador argumentativo "além" estabelece, entre as expressões, uma relação de soma com a finalidade de direcionar a argumentação para uma mesma conclusão, ou seja, muitos sofrem "com o maxismo (sic) e o desrespeito de homens ignorantes" (linhas 8 e 9). Na linha 9, o processo argumentativo é 
baseado na argumentação do antimodelo. Segundo Abreu (2009, p. 61), "fala naquilo que devemos evitar". Nesse caso, a postura destes "homens ignorantes, onde eles demostram seu desamor pelo próximo (sic)."

\section{Considerações finais}

Após a análise dos dados, por meio do corpus constituído, constatou-se que os sujeitos se esforçaram para manter alguns traços prototípicos do gênero Carta do leitor. Quanto à interlocução, é estabelecida e mantida pelo uso de pronomes, verbos e expressões de valor vocativo. Ademais, os sujeitos estabeleceram e marcaram, mesmo que, por vezes, de forma limitada, um diálogo com seus interlocutores nos textos produzidos. Compreende-se essa interlocução como essencial, sobretudo, porque contribui para a construção argumentativa do texto. Nos dados analisados, os sujeitos expuseram as suas opiniões por meio de discursos pautados no cotidiano, que possuem fácil adesão, pois retrata o verossímil, aproximando-se, assim, da realidade dos interlocutores/leitores para, em seguida, apresentarem, em alguns gestos, uma argumentação mais consistente nos textos.

Nessa perspectiva de estudo, tem-se constantemente reiterado a relevância do trabalho com gêneros de teor argumentativo, neste caso específico, com a Carta do leitor. Há de se reconhecer o seu potencial retórico-discursivo e linguístico-textual para formação de opiniões acerca de tema circulares e igualmente necessários à emissão de opinião recorrentemente em variadas esferas de atividade humana. Como foi tratado ao longo da discussão apresentada, o deslocamento desse gênero jornalístico à esfera didática e à acadêmica pode promover uma reflexão oportunamente cidadã, sobretudo, por tornar o processo de ensino e aprendizagem de Língua Portuguesa consideravelmente significativo e, por extensão, mais empoderador.

Em última instância, vale dizer que se deve ter a necessária consciência que uma ação pontual, considerando a oferta de um minicurso que se voltou à leitura e à produção de textos opinativos, em especial, a Carta do leitor, foi insuficiente para despertar tal atitude nos sujeitos produtores, tendo em vista que o trabalho com práticas argumentativas orais e escritas deve ser desenvolvido desde a educação básica e constantemente reforçado no ensino superior. Conquanto, reconhece-se que levar tal discussão a efeito em processos de formação docente pode possibilitar um olhar mais acurado em relação a essa demanda que, por muito, urge em níveis e modalidades de ensino diversificados. Ademais, não se pode deixar de chamar a atenção que, mediante os dados analisados, e, principalmente, considerando o grupo 
de participantes com o qual contamos para a realização de nosso estudo, a argumentação deve ser concebida não somente como uma atividade intrínseca à língua(gem), mas uma atitude linguística - tanto no plano retórico quanto no linguístico - que carece de um ensino sistematizado. Os dados, em alguma medida, nos revelaram tal carência.

\section{Referências}

ABREU, Antônio Suárez. A arte de argumentar: gerenciando razão e emoção. 13. ed. Cotia: Ateliê Editorial, 2009.

ALMEIDA, Cláudia Amorim de. Análise retórico-textual do gênero Carta do leitor: algumas estratégias de convencimento/ persuasão. Monografia (Especialização em Pós-graduação em Linguagem e Práticas Sociais). Instituto Federal de Alagoas: Campus Murici, 2018. 84p.

BAKHTIN, M. Gêneros do discurso. In: Estética da criação verbal: introdução e tradução do russo Paulo Bezerra; prefácio à edição francesa Tzvetan Todorov. 4. ed. São Paulo: Martins Fontes, 2003.

BEZERRA, Maria Auxiliadora. Por que cartas do leitor na sala de aula. In: DIONISIO, Ângela Paiva; MACHADO, Anna Rache; BEZERRA, Maria Auxiliadora (Org.). Gêneros Textuais e Ensino. São Paulo: Parábola Editorial, 2010.

CAVALCANTI, Ricardo Jorge de Sousa. Análise textual-argumentativa de processos de retextualização: um cotejo entre a produção oral e escrita de alunos do curso médio técnico e alunos do proeja ensino médio. Tese de Doutorado. Programa de Pós-Graduação em Letras e Linguística da Universidade Federal de Alagoas. Universidade Federal de Alagoas: Maceió, 2016.

O ensino da Argumentação: uma experiência didática com o Artigo de Opinião no Curso de Letras. Dissertação de Mestrado. Programa de Pós-Graduação em Educação da Universidade Federal de Alagoas em Educação Brasileira. Universidade Federal de Alagoas: Maceió, 2010.

FIORIN, José Luiz. Figuras de Retórica. São Paulo: Contexto, 2014.

Introdução ao pensamento de Bakhtin. 2. ed. São Paulo: Contexto, 2017.

; SAVIOLI, Francisco Platão. Para entender o texto: Leitura e redação. 17. ed. São Paulo: Ática, 2007.

KOCH, Ingedore Grunfeld Villaça. A inter-ação pela linguagem. 11. ed. São Paulo: Contexto, 2015.

; ELIAS, Vanda Maria. Escrever e argumentar. São Paulo: Contexto, 2016.

LÜDKE, Menga; ANDRÉ, Marli E.D.A. Pesquisa em educação: abordagens qualitativas. São Paulo: EPU, 1986. 
MARCUSCHI, Luiz Antônio, Gêneros textuais: definição e funcionalidade. In: Gêneros textuais \& ensino. DIONÍSIO, Angela Paiva; MACHADO, Anna Rachel; BEZERRA, Maria Auxiliadora (Org.) São Paulo: Parábola, 2010.

Gêneros textuais: configuração, dinamicidade e circulação. IN: KARWOSKI, Acir Mário, GAYDECZKA, Beatriz; BRITO, Karim Siebeneicher (Org.). Gêneros textuais: reflexões e ensino. 4. ed. São Paulo: Parábola, 2011.

Editorial, 2008.

Produção Textual, análise de gêneros e compreensão. São Paulo: Parábola

PERELMAN, Chaim; OLBRECHTS-TYTECA, Lucie. Tratado da argumentação: a Nova Retórica. Trad. Maria Ermantina de Almeida Prado Galvão; [revisão da tradução Eduardo Brandão]. 2. ed. São Paulo: Martins Fontes, 2005.

REBOUL, Olivier. Introdução à retórica. Trad. Ivone Castilho Beneditti. São Paulo: Martins Fontes, 2004.

SCHNEUWLY, Bernard; DOLZ, Joaquim. Os gêneros escolares - das práticas de linguagem aos objetos de ensino. In: SCHNEUWLY, Bernard.; DOLZ, Joaquim. e colaboradores. Gêneros orais e escritos na escola. [Tradução e organização: Roxane Rojo e Glaís Sales Cordeiro]. Campinas-SP: Mercado de Letras, 2004.

THIOLLENT, Michel. Metodologia da pesquisa-ação. São Paulo, SP: Cortez, 1986.

\title{
RHETORIC-TEXTUAL ANALYSIS OF READER'S LETTER GENDER IN THE ACADEMIC SPHERE
}

\begin{abstract}
This study approaches, based on the composition of the Reader's letter by participants of a mini-course, the subject as a socio-historical and discursive agent in written argumentative linguistic practices. For this, we chose studies that deal with the New Rhetoric (REBOUL, 2004; PERELMAN and OLBRECHTS-TYTECA, 2005) in the interrelationship with Textual Linguistics (KOCH, 2015; KOCH and ELIAS, 2016; MARCUSCHI, 2008; 2010; 2011). The work with the Reader's letter was due to its argumentative and didactic potential. The research is characterized as an action research, in a qualitative perspective of investigation, from the production and analysis of authentic data. The results point out, considering the experience, a certain difficulty in the composition of the genre Reader's letter by the subjects: students and graduates in the Courses of Language and Pedagogy of a given context. This finding leads us to defend the importance of systematized work with the argumentation in initial / continuing teacher education.
\end{abstract}

Keywords: Argumentation. Reader's letter. Written composition. 